\title{
Revision of Sex Hormone Replacement Therapy for CKD Pediatric Cases
}

\author{
Davoud Amirkashani $\mathrm{MD}^{1}$ and Sedigheh Madani $\mathrm{MD}^{2,3 *}$ \\ ${ }^{1}$ Division of Endocrinology and Metabolism, Ali Asghar Children Hospital, Iran University of Medical Science, Tehran, I.R. Iran \\ ${ }^{2}$ Endocrinology and Metabolism Clinical Sciences Institute, Tehran University of Medical Sciences, Tehran, I.R. Iran \\ ${ }^{3}$ Department of Pediatrics, Faculty of Medicine, Baqiyatallah University of Medical Sciences, Tehran, I.R. Iran
}

${ }^{\star}$ Corresponding author: Sedigheh Madani, Endocrinology and Metabolism Clinical Sciences Institute, Tehran University of Medical Sciences, Tehran, I.R. Iran; Tel: +989123715383; Email: Sedigheh_Madani@yahoo.com

Received: November 23, 2021; Accepted: November 26, 2021; Published: November 29, 2021

\section{Letter to the Editor}

According to the North American Pediatric Renal Transplant Cooperative Study (NAPRTCS), children with Chronic Kidney Diseases (CKD) have considerable height deficits in comparison to the normal children. Additionally, short stature and poor growth of CKD children are associated with an increased risk of death [1]. Although complex medical regimens including bicarbonate therapy, iron, erythropoietin, salt-water supplementation, and Growth Hormone (GH) can improve final height, however, these children experience progressive height deficit after the age of $6 y$ compared to their normal counterparts [2]. We believe that CKD pediatric cases with short stature and delayed puberty should receive Sex Hormone Replacement Therapy (SHRT) at the same time when majority of the normal boys and girls have started maturation. We thus propose that SHRT should be started in CKD cases with the same rationale as in hypo/hyper-gonadothropic hypogonadism patients to improve their final height as adults.

\section{Puberty}

Ninety five percent of contemporary normal girls start their Thelarche by the age of 11 y [3] and the mean age of puberty stage $2 a$ and $2 \mathrm{~b}$ in contemporary normal boys are 12.1 and $12.7 \mathrm{y}$, respectively [4]. Sex hormones (estrogen and testosterone) have an essential role in pubertal growth spurt by enhancing synthesis and secretion of IGF1 that has anabolic effects on bone growth plates [5]. Despite good acid-base management and nutritional support, CKD can interfere with the hypothalamic-pituitary-gonadal axis at different levels which leads to delay in onset of puberty [6]. Pulsatile secretion of Luteinizing Hormone (LH) is impaired along with serum LH level elevation in CKD children due to uremia. Lack of nocturnal LH secretion causes delay in puberty in these patients [7]. Pediatricians should evaluate pubertal delay in CKD children, if no Thelarche starts by the age of 11 $\mathrm{y}$ in girls and no sign of puberty at $13 \mathrm{y}$ in boys.

In normal children, standardized height averagely increases 1.3 SDS from pre-puberty to post-puberty, while patients with delayed puberty have significantly less increase in standardized height $(+0.9$ SDS) [7]. CKD Children have approximately 2.5 years lag in the onset and progression of gonadarche in comparison with their peers.
In addition, their pubertal growth spurt is shortened by $1.5 \mathrm{y}$, and at start of the pubertal spurt, they have less mean height velocity in comparison with the healthy adolescents [7-9]. Thus, an irreversible height deficit occurs during puberty in CKD children [9] because of disturbed puberty and impaired pubertal growth spurt.

\section{Growth Hormone}

Practitioners have tried to enhance CKD children growth deficit with $\mathrm{GH}$, however, optimal final height was not achieved with this treatment. In CKD children who received GH from late pre-pubertal stage, GH therapy had no overall effect on the improvement of pubertal height gain and they still had a prominent height deficit $[8,10]$. Also, the mean peak height velocity during the pubertal growth spurt was not significantly higher in GH treated CKD children compared to the control CKD children [8].

\section{Conclusion}

According to the best of our knowledge, CKD girls and boys with short stature who do not start puberty till 11 and 13 y respectively are at high risk of height deficit in spite of GH therapy. As 20 to $25 \mathrm{~cm}$ of FH was obtained by pubertal growth spurt [11], experts have referred this height deficit to the delayed puberty and shorten pubertal growth spurt duration in CKD children [7]. SHRT in boys with CKD and delay puberty is challenging and needs more personalized decision making because Testosterone could aggravate uremic side effects $[12,13]$. However, we recommended SHRT in short CKD girls with delay puberty at $11 \mathrm{y}$ to enhance their final height besides improving bone density.

\section{Conflict of Interest}

On behalf of all authors, the corresponding author states that there is no conflict of interest.

\section{References}

1. Furth SL, Stablein D, Fine RN, Powe NR, Fivush BA (2002) Adverse clinical outcomes associated with short stature at dialysis initiation: a report of the North American Pediatric Renal Transplant Cooperative Study. Pediatrics 109(5):909-13. [crossref]

2. Franke D, Winkel S, Gellermann J, Querfeld U, Pape L, Ehrich JH, et al. (2013) Growth and maturation improvement in children on renal replacement therapy over the past 20 years. Pediatric Nephrology (Berlin, Germany)28(10):2043-51. [crossref] 
3. Cabrera SM, Bright GM, Frane JW, Blethen SL, Lee PA (2014) Age of thelarche and menarche in contemporary US females: a cross-sectional analysis. Journal of Pediatric Endocrinology and Metabolism 27(1-2):47-51. [crossref]

4. Biro FM, Lucky AW, Huster GA, Morrison JA (1995) Pubertal staging in boys. The Journal of Pediatrics 127(1):100-2. [crossref]

5. Grob F, Zacharin M (2020) Puberty in chronic inflammatory conditions. Current Opinion in Endocrine and Metabolic Research.

6. Silverstein D (2018) Growth and Nutrition in Pediatric Chronic Kidney Disease. Front Pediatr 6: 205 doi: 103389/fped. [crossref]

7. Haffner D, Fischer D-C (2012) Growth and pubertal development in dialyzed children and adolescents. Pediatric Dialysis: Springer p. 453-81.

8. Haffner D, Schaefer F, Nissel R, Wühl E, Tönshoff B, Mehls O (2000) Effect of growth hormone treatment on the adult height of children with chronic renal failure. New England Journal of Medicine 343(13):923-30. [crossref]
9. Schärer K (1990) Growth and development of children with chronic renal failure. Study Group on Pubertal Development in Chronic Renal Failure. Acta paediatrica Scandinavica Supplement 366:90-2. [crossref]

10. Nissel R, Lindberg A, Mehls O, Haffner D (2008) Factors predicting the near-final height in growth hormone-treated children and adolescents with chronic kidney disease. The Journal of Clinical Endocrinology \& Metabolism 93(4):1359-65. [crossref]

11. Scheffler C, Hermanussen M (2018) Growth in childhood and adolescence. The International Encyclopedia of Biological Anthropology 1-11.

12. Johansen KL (2004) Testosterone metabolism and replacement therapy in patients with end-stage renal disease. Seminars in Dialysis. [crossref]

13. Zhao JV, Schooling CM (2020) The role of testosterone in chronic kidney disease and kidney function in men and women: a bi-directional Mendelian randomization study in the UK Biobank. BMC Medicine 18:1-10. [crossref]

\section{Citation:}

Amirkashani D, Madani S (2021) Revision of Sex Hormone Replacement Therapy for CKD Pediatric Cases. Endocrinol Diabetes Metab J Volume 5(2): 1-2. 